\title{
Internet resources for law
}

\author{
By Corinne Jacox and Brian Striman
}

\section{Ob, what tangled webs we} weave....

$\mathbf{L}$ aw-related information on the Internet is growing at a fast pace. Sites are in various stages of development. Most of the files within the sites referred to can be read online and are accessed through the use of telnet, gopher, or lynx. A few notable ftp files are also included.

Most of the sites contain combinations of judicial, legislative, executive, constitutional, state, and international law and could be included under several of the topic areas listed in this article. Many of the sites link to each other. Our intention is to give as many stable sites as possible and some of their features. Keep in mind that these sites are sometimes busy.

\section{Legislative sources}

There are several sites for United States legislative information.

- LOCIS (Library of Congress Information Service). Updated daily, this is probably the best single source for federal legislative materials. The files in LOCIS include bills and resolutions from the 93rd Congress (1973) to the current one, including the content and status of legislation, digests of bills, sponsors/cosponsors, and committees of referral. Information about amendments and the full text of most public laws are available beginning with the 97th Congress (1981-1982).

Instructions on searching the various files, searching hours, and how to ftp similar instructions are available inside the menu. Access: Telnet locis.loc.gov (limited to 60 simultaneous users); or via LC MARVEL (Campus-Wide Information System): Gopher gopher.marvel. loc.gov/library of congress online systems/connect to locis.

- Library of Congress World Wide Web. This incredible resource contains hypertext and multimedia documents. That's only the tip of the iceberg. Easy-to-read screens help guide the searcher to find current daily files such as House and Senate committee actions, bills, schedules, and calendars. Many of the menu entries and links are still under construction Access to LOCIS is also available as a menu choice. Searching for terms is accomplished via a traditional gopher search. Access to House and Senate gophers as well as a Congressional Quarterly gopher are also provided. Access: Lynx http://lcweb.loc.gov/homepage/ 1chp.html/global electronic library/u.s. government legislative branch/link to lc marvel congressional information.

- COIN (Columbia Online Information Network). COIN is limited to five simultaneous users and 60 minutes maximum use. COIN is host for a few Government Printing Office (GPO) databases and is still developing. Currently, the GPO Access service offers three fulltext databases: The Federal Register, Congressional Record, and the Congressional Bills. The Congressional Bills are indexed and keyword searchable on files since the start of the 103rd Congress. Access: Telnet 128.206.1.3/login: guest/government center/access the government center/united states of america.

- Counterpoint Publishing. A commercial service that allows users to browse the Code of Federal Regulations (CFR) and the Federal Register(FR). FR files are added daily and limit nonsubscribers to the table of contents and a portion of the notices and articles. Access to the Federal Register: Telnet gopher.internet.com/ login: gopher/counterpoint publishing/united states federal register; or Gopher gopher. 
internet.com/counterpoint publishing/united states federal register.

CFR files are added monthly and limit nonsubscribers to searching the CFR index and Title I General Provisions. Access: Telnet gopher.internet.com/login: gopher/counterpoint publishing/code of federal regulations; or gopher gopher.internet.com/counterpoint publishing/code of federal regulations.

\section{Judicial sources}

In the world of judicial clocuments, there are many sites offering U.S. Supreme Court decisions. Many of the sites go to the Cornell site mentioned below. At this time, there are a very limited amount of other judicial resources.

- Cornell Legal Information Institute (LU). This WWW site provides hypertext access to the archived Supreme Court decisions located at Case Western Reserve University stored in WordPerfect format. The decisions are distributed on the day of the decision under Project Hermes and begin with May 1990. Searches are available by date of decision, topic, party name, and keyword. Access: Telnet www.law.cornell.edu/login: www; or Lynx http://www.law.cornell.edu/lii.table.html; or Telnet fatty.law.cornell.edu/login: gopher.

- Case Western Reserve University. Valuable for ftp files of cases in the U.S. Supreme Court. This transfers documents quickly but requires good knowledge of $\mathrm{ftp}$ and the filename standards used by the Hermes Project. Access: Ftp.cwru.edu/login: anonymous/password: luse your e-mail address]. At the prompt, type "cd hermes." Then type cd "word-perfect."

\section{State law sources}

Most states lack comprehensive databases and documents relating to court decisions, administrative rules and regulations, statutes, session laws, legislative journals, and bills. Currently, there is a smattering of states like Oregon, Utah, Minnesota, California, Texas, and Hawaii which are developing more substantial databases. Oftentimes what appears to be a good menu entry has either just a list of bill or session law numbers or access is denied to that database. One of the best individual states for legislative materials is Minnesota. Access: Gopher gopher.revisor.leg.state.mn.us.

States that offer gophers have limited menus and provide information such as directories of senators, legislator's names and phone num- bers, state government job listings, discussion groups, calendars, voter information, weather, and other state news services.

- LC MARVEL (Library of Congress). This is one of the few places to find at least 38 states in one menu selection. Some of the state entries offer instructions on how to connect to their databases and resources directly. LC MARVEL will not always provide direct links to the remote state sites. Use of Jughead (found under Internet resources) to search the term "state*" will provide at least nine pages of all kinds of individual state information and a search under individual state names produces some hits that may be useful. Access: Gopher marvel.loc.gov/government information/state and local government information.

\section{Specialty law topics}

The host sites below use Jughead software to aid in searching the abundant menu offerings dealing with a variety of special law topics.

- Washington and Lee University. This is one of the best law "jewels" in all of gopherspace. Jughead searching of words like "law" and/or "leg*" will produce over 10 screens of menu options. Specialty law topics included are laws relating to disabilities, the Internet, adoption, copyright, and environment. There are also extremely valuable links that directly connect the user to law menus in many other gopher sites. Access: Gopher liberty.uc.wlu.edu/ libraries and information access/law/law related sources; or telnet liberty.uc.wlu.edu/login: lawlib/password: lawlib.

- Rice University (Houston, Texas). This wonderful site offers gopher, telnet and www. A more extensive version of Ricelnfo is available via the WWW browser software tools Mosaic or Lynx. The WwW version with hypertext works very well as it provides the reader with a host of information and definitions on Internet-related jargon like HTML, URLs, yahoos providers, http, and gophers.

Special law topics such as copyright law, natural law and natural rights, women and law, and world constitutions are available, as well as links to selected law libraries and archives of law-related discussion lists (some of which have WAIS searching of file texts). Access: Gopher riceinfo.rice.edu/information by subject area/government, political science and law; or Lynx http://riceinfo.rice.edu/information by subject area/government, political science and law. 


\section{International law sources}

There are several sites that include offerings from many international countries. When searching for international documents, the searcher must be aware that some documents are written in their vernacular and may not be readable online.

- SunSITE (University of North Carolina). Choices in this gopher include entries containing Australian documents, basic law of Hong Kong, Canadian documents, German documents, selected treaties, and other miscellaneous international documents. Access: Gopher sunsite.unc.edu/worlds of sunsite/law and legal studies/united nations justice network/ foreign and international law.

- InforM (University of Maryland at College Park). Jughead searching offers a rich pool of legislative, judicial, and other law-related information from which to draw. One of this site's strengths is that it pulls together many international gopher sites. When going into this site using Lynx, the hypertext screens will look slightly different, but the databases and contents seem to be the same. Access: Gopher inform.umd.edu/educational resources/academic resources by topic/united states and world politics, culture and history/resources by continent; or telnet inform.umd.edu; or telnet inform.umd edu/login: lynx/academic resources/united states and world politics, culture and history/continent resources.

\section{Other resources}

- Saint Louis University SLUVIEW. The law library portion of this gopher site contains many miscellaneous resources. It is definitely worthwhile spending time investigating its contents. Access: Gopher sluvca.slu.edu/library services/slu law library services.

- Washburn University WASHLAW. The law-related, well-organized menus include a wide variety of files such as lawyer jokes, Holocaust Information System, virtual reference desks, and many law-related gophers. Access: Telnet lawlib.wuacc.edu/login: washlaw.

- The Legal List, Law-Related Resources on the Internet and Elsewhere. Compiled by Eric J. Heels, this is a valuable resource for finding law-related information on the Internet. This list is free on the Internet, but costs if you print it. Online access: Gopher gopher.sluvca.slu.edu/ library services/slu law library services/law-related gophers and information servers; or access via anonymous ftp: $\mathrm{ftp} \mathrm{ftp}$.midnight.com.
- Internet Sources of Government Information. Compiled by Blake Gumprecht, this is a useful tool to find out what government information is available. It is organized into major topic areas which are arranged alphabetically. The most useful section for legal resources is "Political Science, Law and Government." Online access: Gopher una.hh.lib. umich.edu/inetdirs/guides on the social sciences/government; or anonymous ftp: ftp una.hh.lib.umich.edu/user: anonymous/password: e-mail address/cd inetdirsstacks/get government: gumprecht. (Ed. note: A portion of Gumprecht's resource list appeared in CERL News, January 1994.)

- Law Lists. Compiled by Lyonette LouisJacques, this document lists a wide variety of law-related discussion groups. Instructions for subscribing to these groups are included. $A C$ cess: Lynx http://www.kentlaw.edu/legal domain network/law lists; or Gopher gopher. kentlaw.edu/search all menus on this gopher/ [search term "law lists"].

\section{UseNet newsgroups}

Access to UseNet newsgroups varies according to local providers. Check with your system administrators for access information to these selected newsgroups: bit.listserv.ada-law, claricourts, claribiz.courts, clarilaw, clari.law.civil, clari.law.supreme, courts.usa federal.supreme, misc.legal.

- The Legal Domain Network (ChicagoKent College of Law). This provides a single place with read-only access to law-related Usenet articles in a "threaded" fashion to consolidate all substantive legal discussions. Indexed with WAIS, each listserv will have different retention policies. Access: Gopher gopher.kentlaw.edu; or Lynx http://www.kent law.edu/lawnet/lawnet.html/law/listserv.

\section{Conclusion}

Remember to use searching tools such as Veronica and Jughead. Also, once inside a file, use of the " $\mathrm{p}$ " or " $\mathrm{m}$ " command allows the document(s) to be e-mailed directly to the user's e-mail account.

When using the Internet, remember that the resources are constantly changing. Be sure to read the introduction screens carefully. What was available one day may not be available the next. Source and file names change without notice and files that look enticing may be under construction. 


\section{Brodart Academic Book Services}

\section{is pleased to introduce its new sales representative Gerald Stormer.}
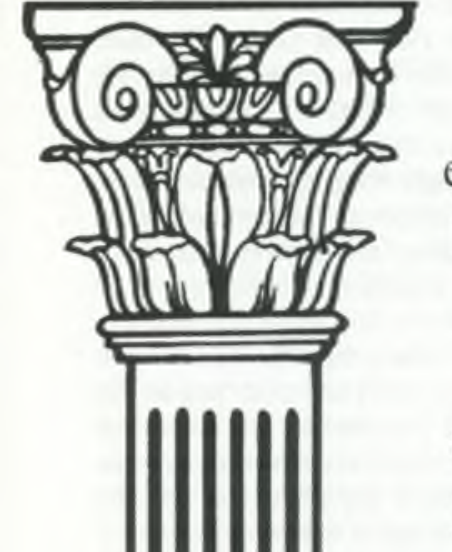

Mr. Stormer brings to

Brodart ten years of

experience in the academic library world and is eager to assist you in reaching your library's high standards. With over fifty years of book distributing experience supported by an over 1.7 million title database, and innovative electronic systems, plus Brodart's dedication to customer service, you are assured the finest in materials selection. Brodart's Academic Book Services can be reached at 800-233-8467, ext. 550.

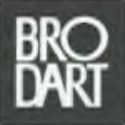

\section{Brodart Academic} Book Services 